\title{
Evolution FP7 funded project: body structure design strategies using new composite and aluminium materials and enabled technologies
}

\author{
Elena Cischino \\ Pininfarina S.p.A., \\ Via Nazionale 30, Cambiano 10020, Italy \\ Email: e.cischino@pininfarina.it
}

\section{Cristina Elizetxea}

\author{
Fundacion Tecnalia Research and Innovation, \\ Mikeletegi Pasalekua 2, \\ Donostia-San Sebastián E-20009, Spain \\ Email: cristina.elizetxea@tecnalia.com
}

\section{Iratxe Lopez}

FPK - Batz S. Coop. Torrea, 2, 48140 Igorre (Bizkaia), Spain

Email: ilopez@batz.es

\section{Zina Vuluga}

ICECHIM - Institutul Naţional de Cercetare Dezvoltare pentru Chimie si Petrochimie, Splaiul Independenţei 202, Bucureşti 060021, Romania

Email: zvuluga@yahoo.com

\section{Mikelis Kirpluks}

IWC - Latvijas Valsts Koksnes Kimijas Instituts, Dzerbenes st. 27, LV-1006, Rīga, Latvija Email: mkirpluks@edi.lv

\section{Peteris Cabulis \\ RITOLS, \\ Dzērbenes iela 27, LV-1006, Rīga, Latvija \\ Email: peteris@ritols.lv}




\title{
Jesper deClaville Christiansen and Catalina-Gabriela Sanporean*
}

Aalborg University,

Fibigerstraede 16, Aalborg 9220, Denmark

Email: jc@m-tech.aau.dk

Email: gabi@m-tech.aau.dk

${ }^{*}$ Corresponding author

\section{John P. Deverill}

AMRC with Boeing,

University of Sheffield,

Advanced Manufacturing Park,

Wallis Way, Catcliffe,

Rotherham, S60 5TZ, UK

Email: j.p.deverill@sheffield.ac.uk

\section{Francesca Di Paolo}

Soc. Cons. Innovazione Automotive e Metalmeccanica a r.l.,

Via Nazionale snc,

Santa Maria Imbaro 66030, Italy

Email: fdipaolo@innovazioneautomotive.eu

\section{César Maestro and Estibaliz Alcalde}

Cidaut Fundación para la Investigación y Desarrollo en

Transporte y Energía Aleixandre Campos 2,

Boecillo 47151, Spain

Email: cesmae@cidaut.es

Email: maralc@cidaut.es

\section{Enrico Mangino}

Centro Ricerche Fiat S.C.p.A.,

Strada Torino 50, Orbassano 10043, Italy

Email: enrico.mangino@crf.it

\begin{abstract}
Based on Pininfarina Nido EV concept, EVolution aims to reduce the vehicle weight through new materials and process technologies, focused on five demonstrators: underbody, front crossbeam, mechanical subframe, shotgun system and door. This paper refers to body structure design strategies using new composite, Al materials and enabled technologies, focusing in particular on demonstrators design and manufacturing. The new front crossbeam geometry of the front shell is adapted starting from the Nanotough design, while the rear shell is specific for EVolution. The subframe demonstrator is redesigned to fulfil mechanical requirements of the part and manufacturing feasibility either. The EVolution door concept consists of two semistructural
\end{abstract}


composite skins including a structural $\mathrm{Al}$ frame. The underbody is conceived through an integrated approach, optimising each element for its function. The shotgun component is designed to link parts obtained with different manufacturing technologies and several aluminium alloys in one single component: the structural node demonstrator.

Keywords: body in white; lightweighting; composites; aluminium; electric vehicles.

Reference to this paper should be made as follows: Cischino, E., Elizetxea, C., Lopez, I., Vuluga, Z., Kirpluks, M., Cabulis, P., deClaville Christiansen, J., Sanporean, C-G., Deverill, J.P., Di Paolo, F., Maestro, C., Alcalde, E. and Mangino, E. (2017) 'Evolution FP7 funded project: body structure design strategies using new composite and aluminium materials and enabled technologies', Int. J. Automotive Composites, Vol. 3, Nos. 2/3/4, pp.251-275.

Biographical notes: Elena Cischino joined Pininfarina in 2001, since which she has had several roles: NVH Performance Engineer of Ford StreetKa; CAE Manager (Jaguar X-type Estate, Citroën C4 for China market); Vehicle Performance Manager (Alfa Romeo Spider, Maserati Granturismo); Project Manager of concept feasibility (D-segment vehicle family for Chery Automobile). She is currently the Engineering Manager of the Pininfarina R\&D Department, the Technical Coordinator the FP7 EVolution project Consortium and member of the Advisory Board of the FP7 UrbanEV project. She has More than 20 years of experience in Automotive Industry, Her main fields of interest are the innovative architectures of car body structures, combining performant design with a multimaterial approach, and alternatives powertrain layout. She graduated with honours in Mechanical Engineering at Politecnico of Milano (1996) with a thesis awarded as the best of the year in the power transmission environment.

Cristina Elizetxea graduated in Chemical Science in the University of Basque Country (1992) and with a PhD in Chemistry in the University of Basque Country (2000), is currently member of the research staff of Industry and Transport Division Lightweight Group at TECNALIA. She has more than 20 years of research experience in the field of composite materials mainly oriented to thermoplastic Technologies. Since the last six years, her main activity has been focused in the industrialisation of the in-situ polymerisation and moulding process of anionic APA6, for Automotive continuous fibre thermoplastic composites. Three patents, two $\mathrm{PhD}$ Thesis, industrial projects and several scientific contributions to workshops and congress complete her expertise.

Iratxe Lopez is an Industrial Engineering degree. From 1998 to 2000, she worked as Research Engineer at SOLMICRO carrying out quality product control. In 2000, she joined to IKERLAN as Research Engineer collaborating in different projects in areas of configuration, maintenance, and supply of logistic system. Since 2002, she is working in FPK Lightweight Technologies, initially as development engineer providing support in different development projects. From 2005 to 2008 , she worked as development project leader, leading the design and manufacturing of parts. In 2008, she specialised in research projects and she works now as research project leader, being the person in charge of research projects in FPK. She has been involved in several projects with experience in both State and European programs. She coordinates different partnerships and leads the research project team in FPK. 
Zina Vuluga, PhD, Leader of the research team "Polymer Composites and Nanocomposites", 1st degree Senior Researcher, Vicepresident of the Scientific Council of INCDCP-ICECHIM. She received her $\mathrm{PhD}$ in Chemical Engineering from 2004, thesis at "Politehnica" University of Bucharest, Faculty of Industrial Chemistry, in "Thermoplastic Composites" (at nanometre scale), MS in Chemistry and Technology of Macromolecular Compounds, "Politehnica" University of Bucharest, Faculty of Industrial Chemistry 1980. She has over 30 years of experience in obtaining polymer composites and over 10 years in obtaining polymer nano-composites. She is also member of the Romanian Association of Polymer Science (ARSP), of the Romanian Association for Materials (ARM), of the Biomaterials Romanian Society and of Chemistry Society from Romania. Ing. Vuluga main research fields are the development of natural and/or synthetic polymer based nano-composites with different nanofillers (layered silicate, titania aerogel, calcium phosphates, carbon nanotube) for industrial and biomedical application.

Mikelis Kirpluks is a Master degree in Chemical Engineering, with a $\mathrm{PhD}$ expected in 2017. He is a researcher at Latvian State Institute of Wood Chemistry, Polymer Laboratory. 16 publications, and the participation in eight European funded project complete his profile.

Peteris Cabulis graduated at Riga Technical University. He is project manager at Ritols.

Jesper deClaville Christiansen, Professor, PhD, at Aalborg University (AAU) in Materials Science and Honorable Professor of Ludong University, Yantei, China. He was knighted by her Majesty the Queen of Denmark. Subjects are mechanics of polymers, polymer physics and chemistry, structure/properties, diffusion, rheology and micro and nano-materials. He was coordinator of the EC Green Car project, EVolution, aiming to lightweight cars and coordinator for the EC Nanotough project with focus on advanced polymeric nano-composites for automotive and space applications. He is Head of the Doctoral Program in Materials Science and Mechanical Engineering at the Faculty of Engineering.

Catalina-Gabriela Sanporean, $\mathrm{PhD}$, is an Associate Professor at Aalborg University, Faculty of Engineering and Science, Department of Materials and Production. She has been awarded with two $\mathrm{PhD}$ : one in Chemical Engineering and one in Mechanical Engineering. She has 11 years' experience in the field of obtaining polymeric nanocomposites for different end uses, such as: automotive industry, packaging industry and biomaterials; morphological and mechanical characterisation of nanomaterials and study of drug release process of bioactive substances from biomaterials.

John P. Deverill is a compression moulding lead engineer at the AMRC. He (Hons.) is a Research Engineer with 12 years of experience in composite materials development/process improvement and component/tooling design/ manufacture for aerospace and automotive applications. He was the lead engineer on the FP7 e-Light and Evolution projects.

Francesca Di Paolo hold a Master degree in Mechanical Engineering at University of Rome - La Sapienza, and after a work experience for an automotive LE. She is currently working within IAM as technical support for European Funded Projects. She was the IPR and Exploitation Manager of FP7 EVolution project. 
César Maestro is a mechanical engineer working in the Materials Process Product Department in Cidaut. He has been working in more than 15 R\&D projects in the last 10 years, most of those in relation with automotive sector, mainly within the active safety field and design of vehicle components. His main expertise is in product development and engineering; he has worked on materials fatigue and durability studies for more than 10 years and is currently involved in the Evolution and ALIVE FP7 Projects.

Estibaliz Alcalde is a mechanical engineer with long experience in casting process. She has participated as Project Manager in different development projects linked with the manufacturing of parts with light alloys, aluminium and magnesium. She mainly focused in the optimisation of process parameters and redesign of components to achieve good quality and avoid casting defects. Her main expertise is in numerical software to simulate casting processes and mathematical models to represent fluid-dynamics characteristics of metal flow and mechanical behaviour of solid components.

Enrico Mangino is graduated in Mechanical Engineer at Politecnico of Turin in 1992. He works in CRF since then about polymeric materials: initially focused on polymeric processes numerical analyses, also coupled with structural analyses, he extended his experiences with the design of polymeric components and manufacturing problem solving. He has been involved in many European projects and Thematic Networks working as local leader and automotive applications expert, referring to polymeric components. He is involved in FCA's innovation activities about polymers.

This paper is a revised and expanded version of a paper entitled 'EVolution FP7 funded project - body structure design strategies using new composite and Al materials and enabled technologies' presented at Industrial Technologies, Amsterdam, 22-24 June, 2016.

\section{Introduction}

Global trends toward $\mathrm{CO}_{2}$ reduction and resource efficiency have significantly increased the importance of lightweight materials over the last years: the European Commission has set severe targets for average new car $\mathrm{CO}_{2}$ emissions of $95 \mathrm{~g} / \mathrm{km}$ by 2020 , and the forecast for 2030 is to reduce emission down to $75 \mathrm{~g} / \mathrm{km}$.

Weight reduction directly decreases the energy consumption and then the $\mathrm{CO}_{2}$ emissions, as the energy required for moving a vehicle is, except for aerodynamic resistance, directly proportional to its mass, enabling as a consequence the downsizing of powertrain and braking system and providing additional weight saving (Stichling and Hasenberg, 2011).

This matter becomes particularly interesting for electrified powertrains, whose diffusion is crucial to reduce the $\mathrm{CO}_{2}$ emissions: currently, the traction battery cost and the range of autonomy are among the most limiting factors to full electric vehicles (FEVs) market penetration. As a rough estimation, considering the battery costs for the year 2015, each slot of vehicle weight reduction of $50 \mathrm{~kg}$ implies a battery cost decreasing of about $500 € /$ car. This cost reduction can compensate the additional cost due to lightweighting, contributing to market penetration of EVs (Fassbender et al., 2012). 
Representing about $40 \%$ of total vehicle weight, the body in white (BiW) is the heaviest vehicle element, hence the implementation of lightweight measures here appears effective.

Extreme lightweight packages, as a combination of specific metallic alloys and highperformance composites for structural parts, are the most relevant to achieve a consistent weight reduction (Wang et al., 2016), even if they imply a superior cost. This is a big challenge for Automotive industry: respect to the Aerospace one, where composites are largely used, Automotive has unique limiting factors including surface finish and impact performance requirements (Elmarakbi et al., 2016), manufacturing cycle time, joining manufacturing infrastructure and production volumes.

The key to success for $\mathrm{CO}_{2}$ reduction relies on the conception of a new FEV Body archetype characterised by extreme lightweight countermeasures, balancing the cost due to lightweighting with the downsizing of the traction battery.

\section{EVolution project goals}

EVolution (FP7/2007-2013, GA n. no. 314744) stands for "The Electric Vehicle revOLUTION enabled by advanced materials highly hybridised into lightweight components for easy integration and dismantling providing a reduced life cycle cost logic".

EVolution started in November 2012 and involves 24 partners from 11 different EU countries, with the goal to demonstrate the sustainable production of a full electric $600 \mathrm{~kg}$ vehicle (FEV). The project ended in October 2016.

EVolution project is principally based on Pininfarina Nido concept, on part of the outcomes of the FP7 project, E-light (2010), based on Nido structure, and on the internal Pininfarina research project Safety Car, ${ }^{1}$ developed around the first Nido archetype, winner of the "Compasso d'Oro" award and placed in the temple of modern art, the MoMA of New York.

Nido concept, fully electric, is an A-segment car conceived as a multifunctional rolling chassis plus a non-structural upper frame, fully in Aluminium, composed by commercial extruded profiles and casted parts, carrying cold-formed panels (Figure 1). Main body sections were obtained assembling different profiles, with a consequent weight increasing even where it is not necessary, as the principal focus of this concept was to save cost, not mass: BiW weight of this solution was $160 \mathrm{~kg}$, while current estimated full vehicle weight was about $850 \mathrm{~kg}$.

Featuring $2+1$ places, 2 doors and a modular rear end for Van and pick-up versions, Nido has been conceived for a small series business case (within 1000 units/year).

EVolution project is focused on some specific body areas, named demonstrators, to be redesigned and lightweighted (50\% weight saving over existing steel equivalent) through an innovative mix of design strategies, materials and processing technologies, to potentially achieve the project goals in terms of weight reduction. To minimise materials costs and supply chain complexity associated with such a large number of potentially suitable materials, EVolution is addressed on a minimum number of them, identified among the existing ones in terms of use, the potential for further development, costeffectiveness and environmental impact. 
Figure 1 Nido concept (left) and Nido BiW (right) (see online version for colours)
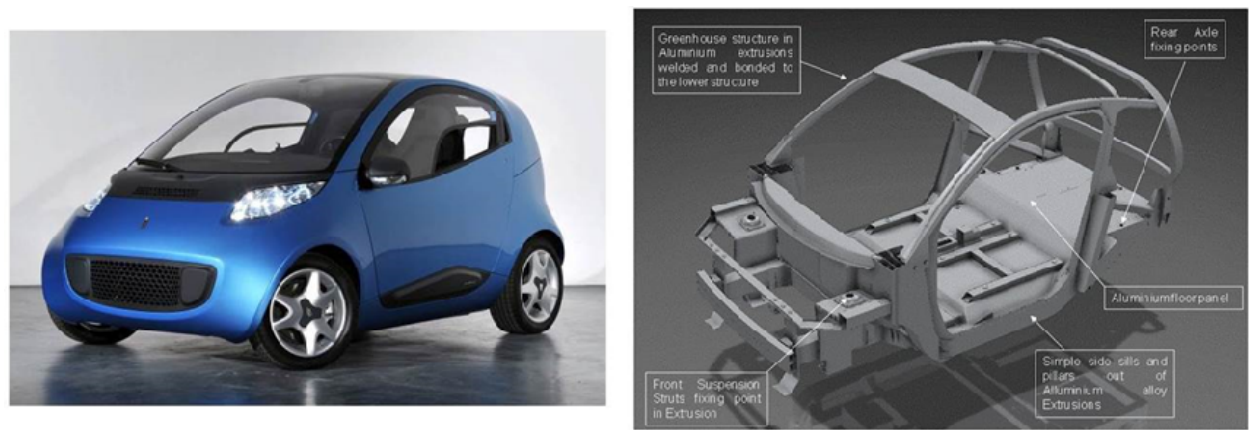

Selected demonstrators are: the underbody, the side door, the front crossbeam, the structural node (shotgun system) and the front mechanical subframe.

Nido BiW, fully in aluminium, was redesigned to be a media to integrate the demonstrators, following the approach to lightweight everywhere reinforcing only where it is necessary, while accomplishing structural performances, crashworthiness included.

To catch this goal, two activities have been conducted:

- $\quad$ The Nido concept bill of materials (BOM) analysis, to single out the areas of potential weight reduction with the associated rough mass saving estimation: this allowed to define a weight target for the BiW (100-115 kg), which was the system interested by project analysis;

- The analysis of future trends of components of the traction chain, in particular, the battery, with the aim to reduce weight.

Next paragraphs will provide more details on the five demonstrators engineering and manufacturing.

\section{Front bumper crossmember}

The current solutions in a front bumper beam component for the mass market are basically made of metal, and only with few notable exceptions, they are hybrid components (Belingardi et al., 2014).

In EVolution project it has been developed and prototyped a full plastic-based structural front bumper beam, taking as a reference and improving the same component developed in a previous FP7 project, named Nanotough (2012), designed using PP reinforced with $\mathrm{NC}$ and GF.

Nanotough concept had a high toughness, but its stiffness did not fulfil the impact requirements, so basing on the AZT protocol and the ECE94 Full Front Crash simulations, different designs and raw materials were analysed to achieve the optimum performance/lightening ratio, bringing the demonstrator to the engineering sign-off concept definition (Figure 2). 
Figure 2 Simulations results based on: (a) AZT protocol/CAE and (b) calibration test/CAE (see online version for colours)
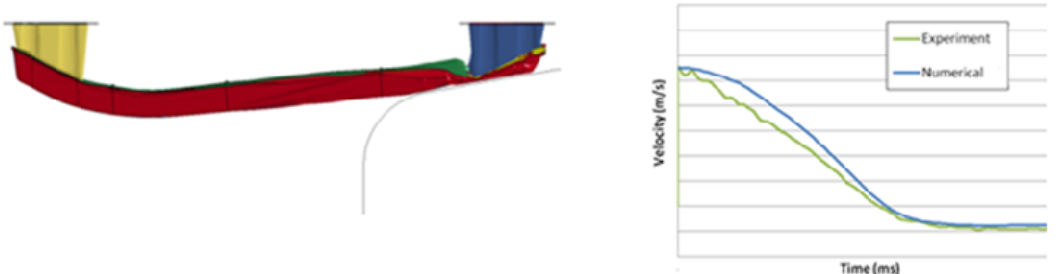

a.
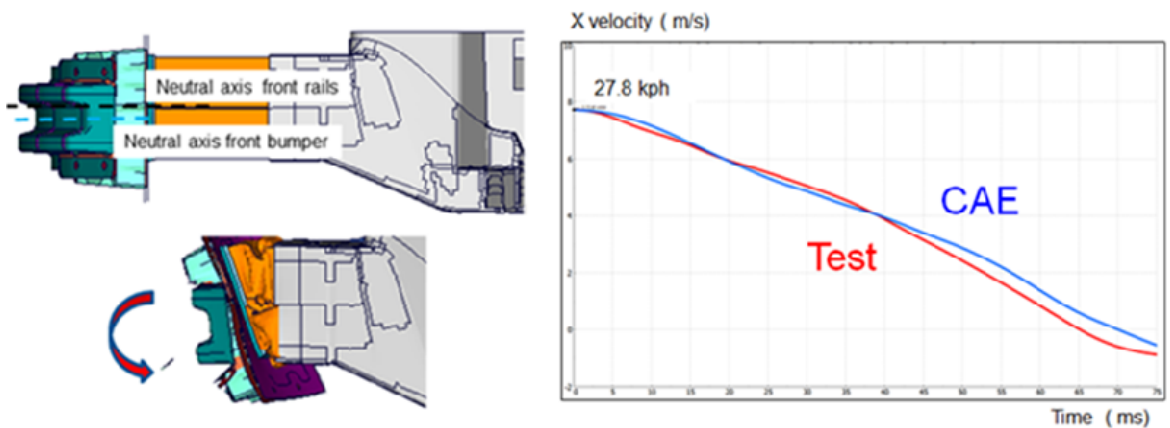

b.

The new beam design consisted of two components, front and rear beam shell members. The geometry of the front shell has been adapted starting from the Nanotough design, keeping in account the characteristics of the several raw materials selected and the different manufacturing processes, while the rear shell is specific for EVolution (Figure 3). A core of specific rigid polyurethane (PUR) foam has been inserted in selected beam sections to improve crash performances. For project purposes, rigid PUR foams were developed from sustainable raw materials. The crash boxes, completely new, were characterised by a different strategy of energy absorption from the previous project (structural PUR foam in place of internal ribs).

Figure 3 Nanotough concept (left) and evolution front crossbeam demonstrator (right) (see online version for colours)

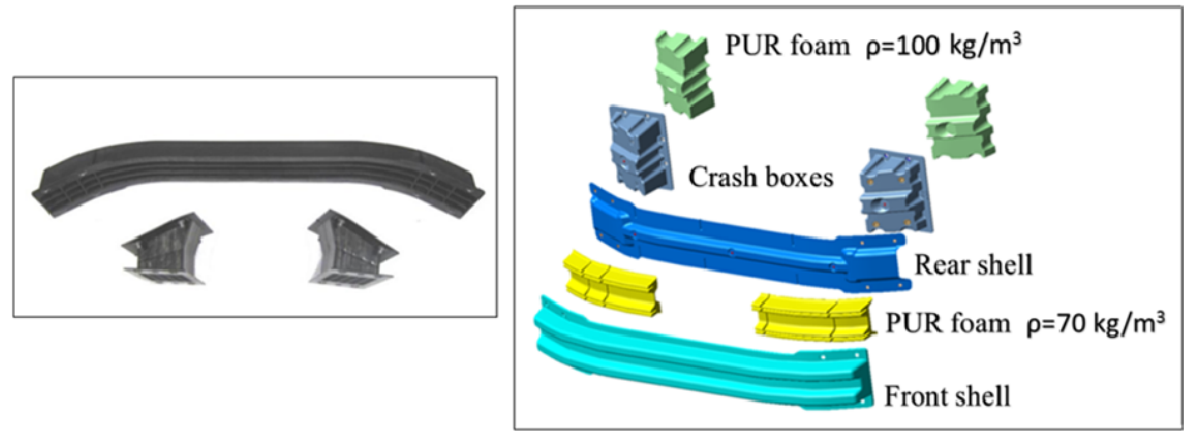

As for the above, target weight (50\% weight saving over existing steel equivalent) was set referring to Nanotough steel baseline crossbeam, derived from a B-segment vehicle, and not from Nido state-of-the-art. 
Final weigh reduction (more than 50\% respect to the steel baseline), and crush test results underline the potentiality of this solution, in terms of raw materials, processes and performances are interesting, especially for medium-high vehicles categories.

\subsection{Specific materials developed during the project for the demonstrator}

Starting from the background knowledge and the results obtained within the Nanotough project, a new polymer material composition as a combination of two key solutions from nanotechnology and advanced materials field (Sanporean et al., 2014) was proposed. Therefore, the composition of the new polymeric material was specially tailored using the advanced material PP with $30-50 \%$ GF in which a special nanosilicate was added. The nanosilicate was evenly embedded into a thermoplastic elastomer matrix to obtain a smart masterbatch (Drozdov et al., 2014; Vuluga et al., 2014, 2016). The masterbach composition and the optimum ratio between components enable its use directly in the extrusion-injection process. Using the masterbatch, a 300\% impact resistance increase compared to virgin PP, without substantially decreasing of stiffness and strength, was obtained due to a synergistically effect between the components ${ }^{2}$ (Figure 4).

Figure 4 EVolution composites properties (left) vs nanotough composites properties (right) (see online version for colours)

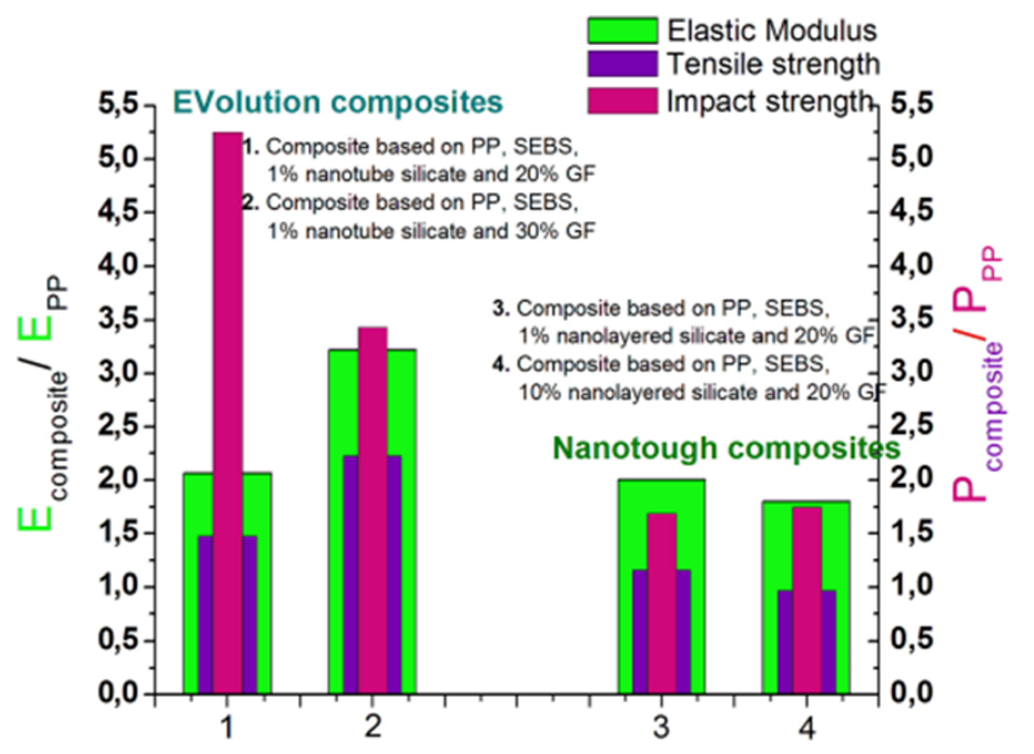

A set of rigid PUR foams based on recycled resources as a core material for cross-beam and crash boxes (Kirpluks et al., 2016) were developed in a very broad range of densities $50-600 \mathrm{~kg} / \mathrm{m}^{3}$. The PUR foam formulation was based on aromatic polyester polyols obtained from recycled polyethylene terephthalate. In developed formulations, sustainable raw material content reached up to $25 \%$ of PUR foam mass. The main innovation was related to the fact that by using sustainable polyols obtained from PET waste it was possible to replace raw materials from petrochemical origin maintaining the same mechanical properties. 
Because the material was intended as impact absorption material usual mechanical strength data at quasi-static loads was not sufficient for the further development of finite element model for crossbeam deformation at impact. Thus mechanical properties at high strain rates were tested to select a material with highest weight reduction.

A CEAST 9340 Drop Tower (Instron) equipment was modified to test compression of material instead of puncture impact (Figure 5). Normally this equipment is used to test materials according to ISO 6603-2 standard. PUR foam cylinders were compressed at a wide range of strain rates (quasi-static testing: $0.002-0.5 \mathrm{~s}^{-1}$; high strain rate testing: $100-300 \mathrm{~s}^{-1}$ ). Obtained stress-strain curves and other data were used in finite element modelling which identified rigid PUR foams with density $70 \mathrm{~kg} / \mathrm{m}^{3}$ and $100 \mathrm{~kg} / \mathrm{m}^{3}$ as the optimal ones to fill the core of crossbeam and crash boxes, respectively.

Figure 5 Testing setup (left) and CEAST 9340 Drop Tower from Instron (right) (see online version for colours)
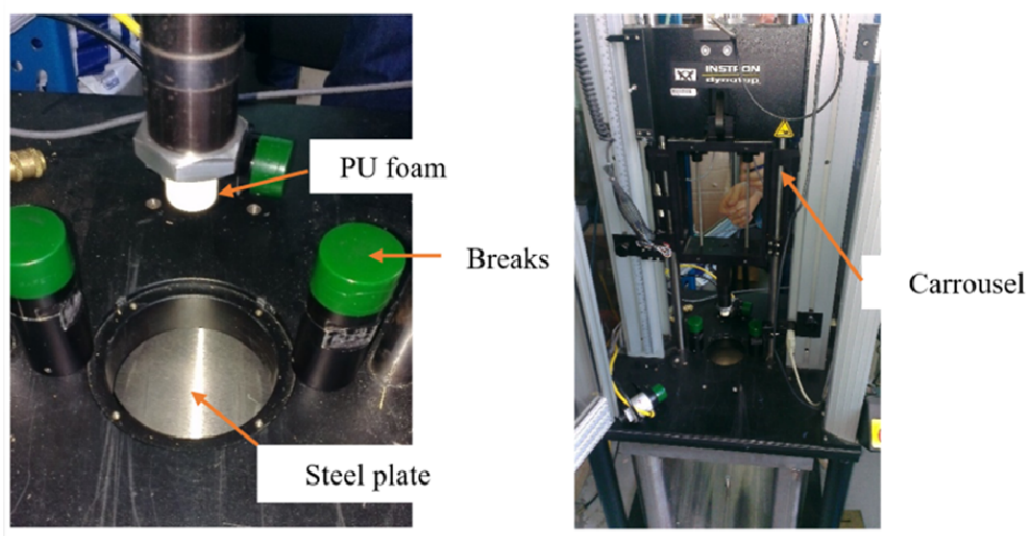

\subsection{The manufacturing process}

The different tools have been redesigned and modified, starting from the Nanotough ones, and other new tools have been manufactured to prototype 'extra parts' that the previous demonstrator had not.

The hybrid technology implemented in the front beam shell member mould was a method that combines in one step press moulding, employing continuous fibre reinforced thermoplastic (based on PP), and injection moulding, using long fibre reinforced thermoplastic (PPGF50) (Dykes and Logue, 2002).

The feeding system of the fabrics has been evolved from Nanotough concept, using a system of spikes instead of a frame.

The injection strategy has consisted of heating the organosheets using an infrared device before the mould closure. Different modifications have been implemented through a set of trials, taking into account also the design constraints of the existing Nanotough tool (Khosrokhavar et al., 2011).

To minimise the tooling cost, taking in account that material volume is similar, both rear shell member and crashboxes have been manufactured by one unique tool.

The reference technology has been injection moulding compounder (IMC), representing a combination of the continuous process of extrusion with the discontinuous 
operation of injection moulding; the parts are produced in a single stage production process. The IMC links a twin-screw compounding extruder, in this case with a specific profile for a proper dispersion of nano-reinforcements, to an injection process, hence it combines two process steps: the material compounding, which normally takes place at the raw material manufacturer, and the injection moulding process, which is usually done at the injection moulded premises. The moulding takes place in a twin platen clamp unit by means of sequential injection in order to have a proper distribution of the nanoreinforcements as well as the GF throughout the part.

The process parameters have been defined by specific simulations and adjusted through several process trials.

Different foam feeding tests carried out on Nanotough geometry, in order to define the filling strategy and the PP/PUR adhesion. To adapt the process to the EVolution beam geometry, a removable elastic element was created.

A series of metallic inserts have been introduced into all parts to improve joint strength of plastic parts and to avoid creep or stress relaxation.

Front and rear shell members have been bonded together with a Polyurethane-based $2 \mathrm{k}$ adhesive, after a plasma treatment of the surfaces, subsequently, the crossmember and the crashboxes have been bolted together, obtaining the complete demonstrator (Figure 6).

Figure 6 Evolution front bumper crossmember demonstrator prototype (see online version for colours)
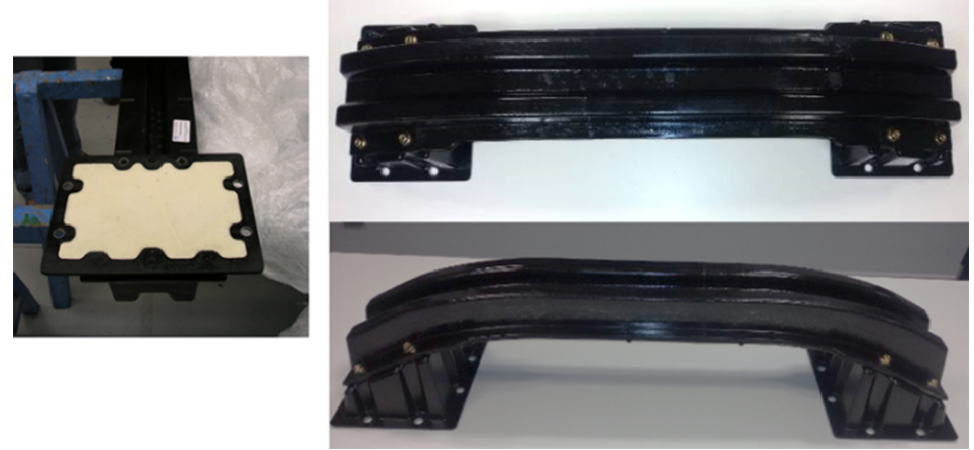

\section{Mechanical subframe}

Subframes are structural modules designed to carry specific automotive components as vehicle suspensions.

The Nido subframe solution, made of steel, consists of three welded components (the main body, the stabiliser bar brackets and the brackets reinforcements). EVolution target was to design and prototype a novel plastic based structural component $50 \%$ weight saving over existing steel equivalent.

The strategy of migration from metal to the composite concept was mainly driven by:

- performance (static load cases of braking, bumping and cornering and fixing points dynamic stiffness)

- functional volume definition and constraints surfaces 
- geometry design for low rate cost/lightening composites, taking into account raw material and process

- fatigue resistance capability of the raw material.

Two options have been considered during the development: two composites shells mutually welded (1) and a solid component without hollows with variable thickness (2).

The first concept was characterised by a higher stiffness and lightweighting potential (containing the shell thickness with the usage of a core foam), but the tooling cost was very expensive.

The second solution had significantly lower tooling costs, but required a highperformance raw material to compensate the lower stiffness respect to the other alternative.

Next paragraphs will describe in detail material and technology developed.

The final release of the subframe demonstrator fulfilled the performances (static load and dynamic stiffness) and the weight requirement (3.48 kg as final weight vs. $6.8 \mathrm{~kg}$ as metal baseline weight) (Figure 7).

Figure 7 Nido concept (left) and evolution subframe final demonstrator (right) (see online version for colours)

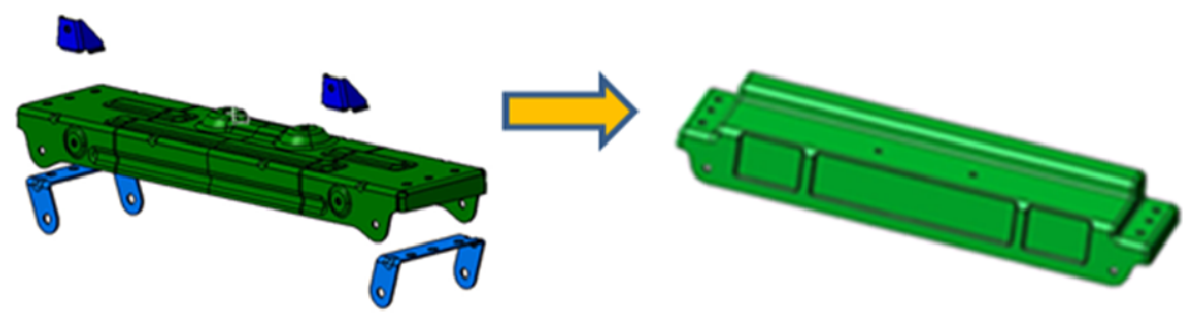

\subsection{Specific material developed during the project for the demonstrator}

The main goal to obtain a composite thermoplastic material with high mechanical properties consists of achieving a good chemical anchorage between the fibres and the matrix.

In the specific case of the subframe, fatigue behaviour and strength were the main mechanical characteristics to be assured.

The fatigue behaviour of any composite is influenced by the toughness of the resin. Polyamide (PA) was considered for the polymeric matrix due to its toughness and low cost. The reinforcement selected has been carbon fibre (CF), superior to glass fibre (GF) in fatigue as well as specific strength.

The CF actually available in the market are chemically designed to be compatible with epoxy resin, but not with thermoplastics as the APA6 (anionic polyamide). A large number of commercial fibres were tested, thermally modifying some of them to improve their compatibility with the PA.

The evaluation of the influence of the de-moulding temperatures took place on APA6/GF due to this parameter impact mainly in the matrix properties (APA6) and not in the fibre type. The conclusions taken from the APA6/GF composite study have been also implemented in APA6/CF composite ones. 
Figure 8 shows the tensile properties of APA6/GF at different de-moulding temperatures.

Figure 8 Young's modulus (left) and strength (right) of APA6/GF composites at different de-moulding temperatures (see online version for colours)
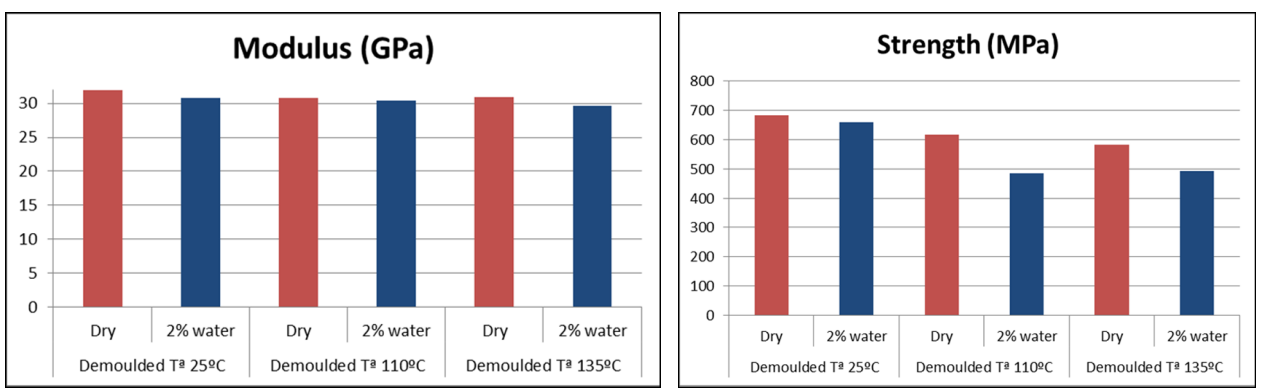

The de-moulding temperature does not have influence in the modulus, less than $3,6 \%$ of the modulus reduction was observed, while the de-moulding temperature has a considerable reduction of the tensile strength value. In the case of dry samples the reduction is between 9.8 and $14.6 \%$ and in the case of wet samples, the reduction is between $25.3 \%$ and $26.5 \%$.

In order to maximise the mechanical properties minimising the cycle time the de-moulding temperature has been fixed in $110^{\circ} \mathrm{C}$.

A specific material optimised for its innovative patented manufacturing process named CAPROCAST (see paragraph 4.2 ) $^{3}$ was developed.

The polymerisation process parameters have been defined taken into account that the polymerisation itself takes place in a mould containing continuous fibre fabrics. Then, fibres selection, manufacturing of samples and mechanical characterisation have been performed.

A subsequent up-scaling activity to demonstrate the viability of in situ APA6 carbon reinforced composites for subframe manufacturing has been done; the APA6/CF material was tested in different demoulding temperatures to improve its mechanical properties and to reduce the moulding cycle, with a subsequent cheapening of the process.

\subsection{The manufacturing process}

CAPROlactam CASTing (CAPROCAST) is a reactive process of in-situ polymerisation consisting of Polyamide 6 (APA6) casting from its monomer, $\varepsilon$-caprolactam.

It is a complex one-step process with a strict control of parameters that have influence during the polymerisation and moulding; the low viscosity of the casting makes it easy to infiltrate the matrix in fabrics and textile preforms.

Basically, the CAPROCAST is an advanced thermoplastic-resin transfer moulding (TP-RTM) technology, enabling the obtaining of structural and complex 3D geometries, reinforced with fibres (García and Palenzuela, 2011; García et al., 2016; De La Calle et al., 2015).

The mechanical properties of the composite material obtained through CAPROCAST technology could be compared with the current thermoplastic composite materials named organosheets (Table 1). 
Table 1 Mechanical properties comparison between caprocast materials and organosheet

\begin{tabular}{lccccc}
\hline \multicolumn{1}{c}{ Material } & & Warp-Weft & $\begin{array}{c}\text { \% fibre in } \\
\text { volume }\end{array}$ & Modulus (GPa) & Strength (MPa) \\
\hline PA 6 Fabric & GF.L & $80 / 20$ & 48 & 31.4 & 670 \\
TECNALIA & GF.T & & & 11.6 & 190 \\
& CF.L & $50 / 50$ & 48 & 48.2 & 629 \\
& CF.T & & & 48.2 & 561 \\
PA 6 & GF.L & $80 / 20$ & 47 & 30.1 & 605 \\
Organosheet* & GF.T & & & 12 & 125 \\
PA 66 & CF.L & $50 / 50$ & 47 & 53 & 785 \\
Organosheet* & CF.T & & & 51 & 725 \\
\hline
\end{tabular}

Source: Bond Laminate

The CAPROCAST process has some advantages over those organosheets:

- Only one moulding process from raw material to final parts (T-RTM process) vs. two processes of the organosheet (sheet obtaining and press-forming step);

- forming of complex 3D geometries, with very depth shapes and complex angles, always keeping a perfect thickness control and a defined orientation of the fibres

- design flexibility to obtain the mechanical requirements: the fibre lay-up and the thickness in each zone of the part can be customised, while the design with the organosheet is subjected to the commercial available materials.

The mechanical subframe design has needed the advantages above. Its $160 \mathrm{~mm}$-depth and its variable thickness, as well as the specific fibres orientation, are difficultly obtainable with a traditional press process.

The demonstrator was redesigned to fulfil mechanical requirements of the part and manufacturing feasibility either. Demoulding angles, textile fabric lay-up, layers overlapping and thickness transition were studied and defined. The raw material used consisted of different sheets of carbon fibre fabrics positioned as a lay-up; for its geometry, a preforming process was necessary, designing the overlaps and keep on the reinforcement continuity. The orientation of the fibres disposed in twelve layers was conceived to assure the mechanical properties.

A new tool has been designed and produced for manufacturing the subframe by means of CAPROCAST technology.

Different feeding simulations have been run to evaluate the filling times and the pressure distribution through the fibres and to set the location of the injection gates, while a set of thermal simulations were carried out to verify the correct heat-cooling strategy required by the production process.

After cutting the twelve textile reinforcement fabrics with the pattern previously defined, the preform was obtained on the malemould applying the vacuum. Then the tool was closed and clamped and the reactive system (caprolactam as well as catalyst and activator systems), was fed into the heated mould.

Once the fibre was completely wet, the polymerisation of the reactive system to polyamide 6 (APA6) occurred. 
Then the part was removed from the mould and milled to refine the contour and to obtain the holes for locating the metallic inserts (Figure 9).

Figure 9 Evolution mechanical subframe demonstrator prototype (see online version for colours)
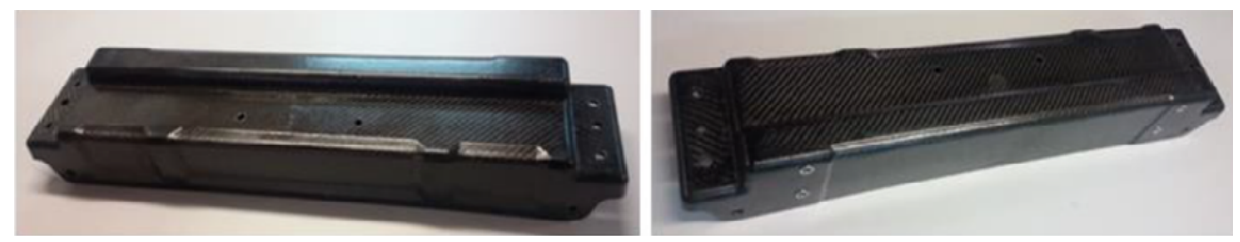

To complete the activities performed during the concept definition, a durability test, representing an important field to be explored with this non-metallic new concept, was performed (Figure 10). According to the most common OEMs standards, the simplified fatigue spectra load (triaxial) was to be applied at the tyre ground point, but this implied the presence of the whole front vehicle suspension. In EVolution project, the suspension was not available, so a specific test (a tensile fatigue test up to $10 \mathrm{kN}$ totally) was designed to derive relevant results.

The component overtook 2,200,000 cycles without breakages, even if deformation of the bushing housings appeared after about 25,000 cycles; all the deformations occurred around the bushing housing, indicating a local lack of performances, but it is important to underline that in a high productivity environment, the bushing insertions would be automatised and would not damage the fabric. Moreover, different bushings with a collar could be used for a more even stress distribution and removal of friction with the lower arms.

Figure 10 Mechanical subframe durability (see online version for colours)

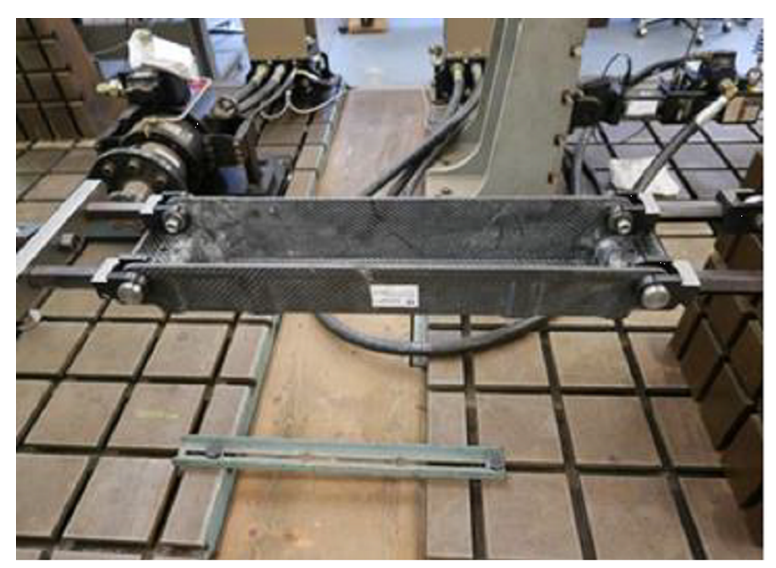

Apart some local design improvement at the level of fixing points, necessary to industrialise the component, the use of continuous fibre thermoplastic composites based on APA6 in situ polymerisation process instead of current metallic material solutions is indeed innovative.

The EVolution subframe is the first component manufactured with thermoplastic composite in the automotive sector with the high mechanical requirement. 


\section{Door demonstrator panels}

The EVolution door concept consists of two semistructural composite skins (inner and outer) including a structural $\mathrm{Al}$ frame. The main idea was to propose an unconventional concept, assuring the main structural and functional performances, cheaper and light weighted respect to baseline Nido door.

Respect to the Smart GmbH vehicle, which presented a similar concept, the novelties proposed into EVolution project were:

- a different technology to produce the skins (compression moulding vs. injection moulding) with lower thicknesses and promising in terms of costs and production time for automotive mass production

- $\quad$ the usage of a bio-based material to manufacture the skins (Biotex Flax)

- $\quad$ an optimised aluminium structure capable to comply to ECE R95 and the crush resistance to quasi-static cylinder intrusion based on FMVSS214 std.

The door skins were conceived using a commercial PP/bio-based material, a thermoplastic commingled balanced $2 \times 2$ twill textile made from natural flax fibre and $\mathrm{PP}$, suitable for rapid processing and reduced weight. More in detail, the outer door skin, requiring an A-class surface finishing, has been conceived as a multilayer where the biobased material was enclosed between two thin sheets of standard PP. Both panels were characterised by low values of thickness ( $\leq 2 \mathrm{~mm})$.

The selected manufacturing process is the compression moulding: an advanced composite material sheet is preheated and then formed through a hydraulic moulding press, featured with matched metal dies.

Given that the process does not involve an injection or transfer cycle, the tooling has less infrastructure requirements than tools designed for other moulding methods. Besides, the cycle time is relative low, so particularly interesting for automotive industry.

A set of samples representing both skins were manufactured by compression moulding and then characterised at laboratory level to obtain the main mechanical properties for FE analysis, keeping in account the effect of the process on the raw semiproduct.

A specific set of structural adhesives and epoxy-based primers were developed to bond the door parts together; aluminium frame elements were joined by self-piercing riveting and MIG-welding.

The integration door-body side was completely new, as the inner skin was not structural, but only functional (Figure 11), hence the lower part of door frame has been designed and dimensioned to have a proper kinematic during the ECE R95 side crash $50 \mathrm{kph}$.

Overall weight reduction of the door frame + skins was around $30 \%$ respect to an equivalent steel solution, but the inner panel can potentially merge the functions of semistructural frame sheet and trim panel, enabling further weight saving on the complete door system. 
Figure 11 The EVolution side door demonstrator (see online version for colours)
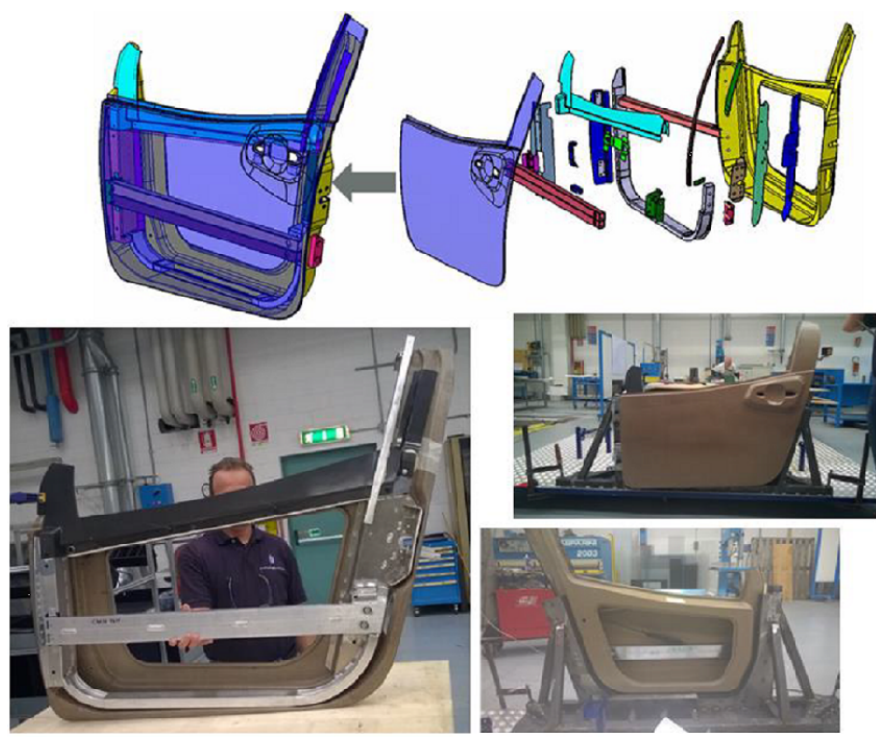

The door complexity as a stand-alone element and integrated system into BiW implied a detailed validation plan:

- A series of CAE analysis on the full vehicle and on the stand-alone component (ECER94 Front Crash 56 kph 40\%ODB; ECER95 Side Crash 50 kph; crush resistance to quasi-static cylinder intrusion based on FMVSS214 standard; door sag, door flexural stiffness, door local stiffness; door mismatching);

- An experimental plan on a series of stand-alone doors, to confirm and to complement the virtual forecasts:

- Panels: Flexural stiffness test, painting test

- Whole door: Door sag; crush resistance to quasi static cylinder intrusion based on FMVSS214 standard (Figure 12); opening/closing durability test in climatic chamber (Figure 13).

Figure 12 From left to right: door flexural stiffness, door sag, door crush resistance tests and test/CAE total average intrusion force (see online version for colours)
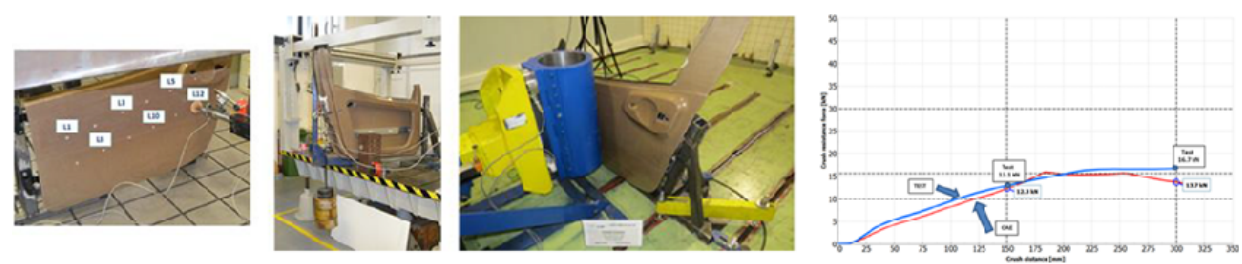

All the validated performances achieved the structural targets, demonstrating, together the virtual analysis on correlated models, that this new concept is equivalent to a full metal door and, what is more, it is lightweighted and industrially viable. The final 
verification of the ECER95 full-scale side crush at $50 \mathrm{kph}$ confirmed the results were in the target (Table 2).

Figure 13 Door opening/closing durability test (35,000 cycles) in climatic chamber (see online version for colours)
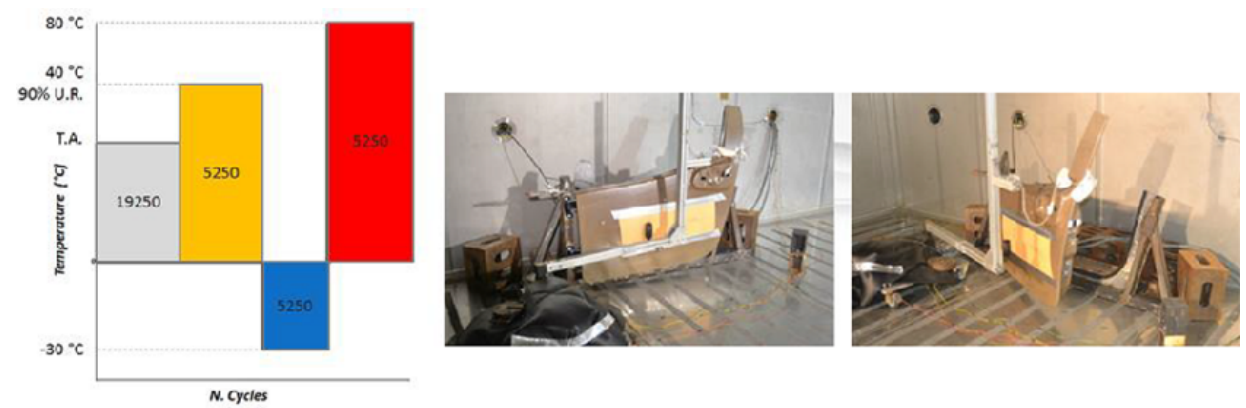

Table 2 Results of the final verification of the ECER95 full-scale side crash

\begin{tabular}{lccc}
\hline Force [N] & Test result & CAE results & Target \\
\hline Initial crush resistance ( 0-6") & 13,081 & 13,600 & $>10,000$ \\
Intermediate crush resistance (0-12") & 16,768 & 27,000 & $>15,600$ \\
Max Reaction Force & 25,274 & 56,100 & $>31,100$ \\
\hline
\end{tabular}

Another important characteristic of the door panels, particularly the exterior, was the surface quality, concurring in influencing the aesthetic of the car, hence the outer panel mould was manufactured in order to achieve an A-class surface.

A special bi-component adhesion promoter, formulated with special polymers interacting with the surface, through the creation of an intimate and permanent adhesion with flamed polypropylene, was applied.

Subsequently, a standard painting cycle at low temperature $\left(60^{\circ} \mathrm{C}\right.$ to dry) was followed. The result, evidenced into EVolution mock-up (Figure 14), was in line with the surface quality requested.

Figure 14 Door mock-up overview (see online version for colours)
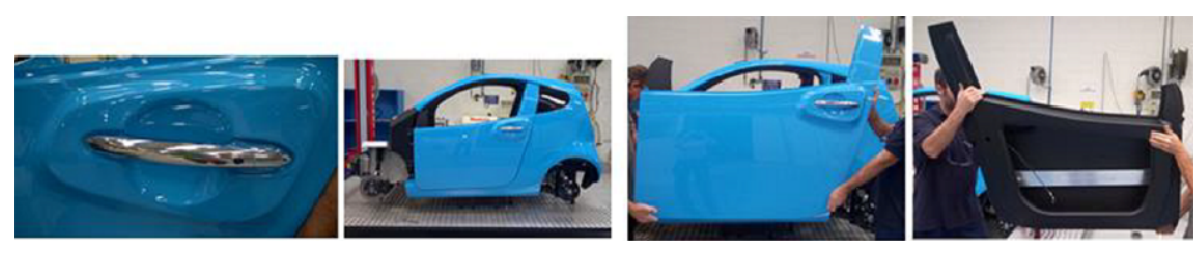

\section{Underbody and structural node (new aluminium technologies)}

Aluminium has been selected as reference lightweight metal to develop two important demonstrators: the underbody (intended as firewall, central floor and associated reinforcements) and the front shotgun system. The same material was considered to develop the $\mathrm{BiW}$, for coherence with the Nido baseline. 
High strength aluminium alloys of $5 \mathrm{xxx}$ and $6 \mathrm{xxx}$ series were considered and improved taking into account the structural performances requested and the selected manufacturing technologies.

\subsection{Underbody demonstrator}

The underbody was conceived through an integrated approach, leveraging new process technologies (D'Annibale, 2014; Harrison et al., 2013) to merge in a unique new component as much parts as possible, optimising each element for its function (Figure 15). This methodology allowed the maximum potential for weight saving with respect to Nido underbody: proposed technologies enabled complex geometries with reduced thickness and a consistent part count reduction. As a final result, EVolution underbody weight is about $20 \mathrm{~kg}$ lightened respect to Nido underbody, fully in aluminium, corresponding to a weight reduction of $47 \%$.

Figure 15 Evolution underbody demonstrator concept (left) and prototype (right), with firewall details (see online version for colours)
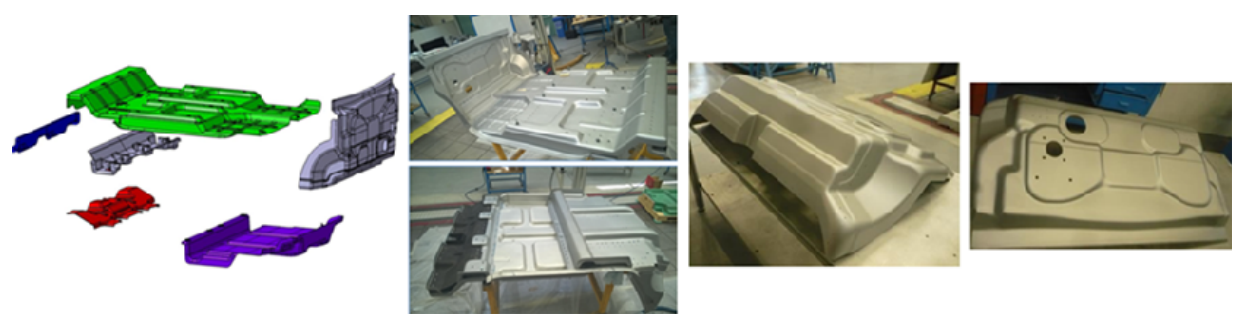

Gas forming is a plastic deformation process for aluminium sheets taking advantage from the higher elongation capabilities of the metal at high temperature. The inert gas plays the role of the punch tool; it is injected from ad-hoc channels placed into a heating plate following a specific pressure curve, and the sheet is formed into its final shape, defined by a matrix tool. Firewall and Central Floor have been designed and manufactured according to this technology.

Parts produced by hot forming are characterised by high strength, complex shapes and reduced springback effects. Shaping a metal at the hot working temperature range requires much less force and power than in cold working. Moreover, at typical hot forming temperature, a metal also possesses far greater ductility than at its cold worked temperature. The much greater ductility allows for massive shape changes that would not be possible in cold worked parts. Rear suspension crossmember was designed and manufactured according to this process, as the front floor reinforcement. In particular, this element showed innovation content also in terms of the use of a multi-thickness raw aluminium sheet to obtain a multithickness component, following the EVolution approach of 'adding material where it is needed', maximising the ratio between performances and weight saving.

CAPROCAST technology, already described in Section 4.2, has been applied to Floor Rear Reinforcement, selecting a specifically developed thermoplastic composite APA6-based reinforced with GF. It was experimentally demonstrated the important capability of this material to survive to e-coating process, enabling to assembly the element as the other metallic BiW parts. 
A set of local test on underbody subassemblies has been executed to correlate the APA6/GF virtual models (Figure 16).

Figure 16 Propaedeutic CAE simulations performed on underbody subassembly (see online version for colours)

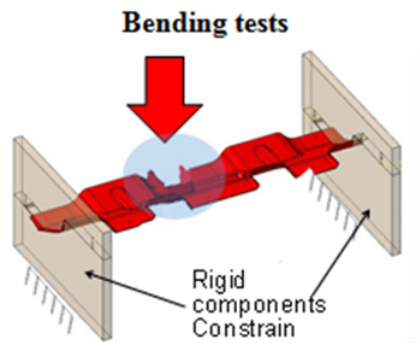

Test \#1 Floor rear reinforcement under bending load

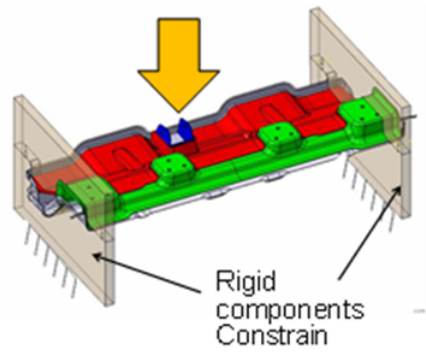

Test \#3 - Rear underbody subsystem under bending load

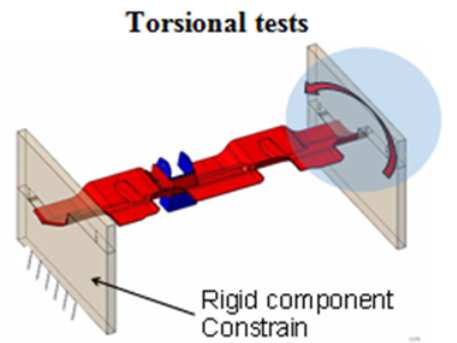

Test \#2 - Floor rear reinforcement under torsion load

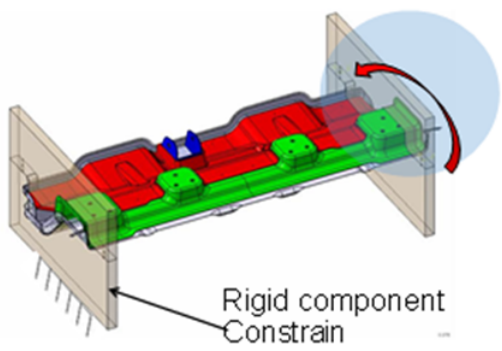

Test \#4 - Rear underbody subsystem under torsion load

\subsection{Structural node demonstrator}

The structural node demonstrator is the assembly of the front shotgun system (shotgun + front rail + reinforcement); it has the relevant function to absorb the energy in the case of a frontal collision (Figure 17).

The shotgun has been manufactured through sand casting process.

CIDAUT's sand casting technology is specific because it uses an electromagnetic pump (EPGS) developed to achieve high mechanical properties in aluminium components with complex geometry, introducing molten aluminium inside the sand mould in a counter gravity way and with a controlled velocity. This means no turbulence in filling stage, so no gas porosity defects in components.

One of the characteristics of any sand mould process is the possibility to perform complex and hollow sections when a core is placed into the sand mould before the aluminium flows inside.

The innovation proposed in Evolution project was to replace the sand core with a structural element, to form a multicomponent part after casting.

Taking into account all these characteristics, the shot-gun component was designed to be a media to link parts obtained with different manufacturing technologies (extrusion, standard profiles, stamping) and several aluminium alloys in one single component: the structural node demonstrator. Hence, shot-gun and front rail are joined together during 
the casting process: extruded profiles were placed as inserts in sand moulds and during the filling process the molten aluminium covers them. Due to solidification shrinkage and the intermetallic surface (based on $\mathrm{Zn}$ and $\mathrm{Al}$ ) created during the solidification, both of them produce a constraint that fixed extruded profiles with casting component.

Figure 17 Evolution structural node demonstrator concept (left) and prototype (right) (see online version for colours)
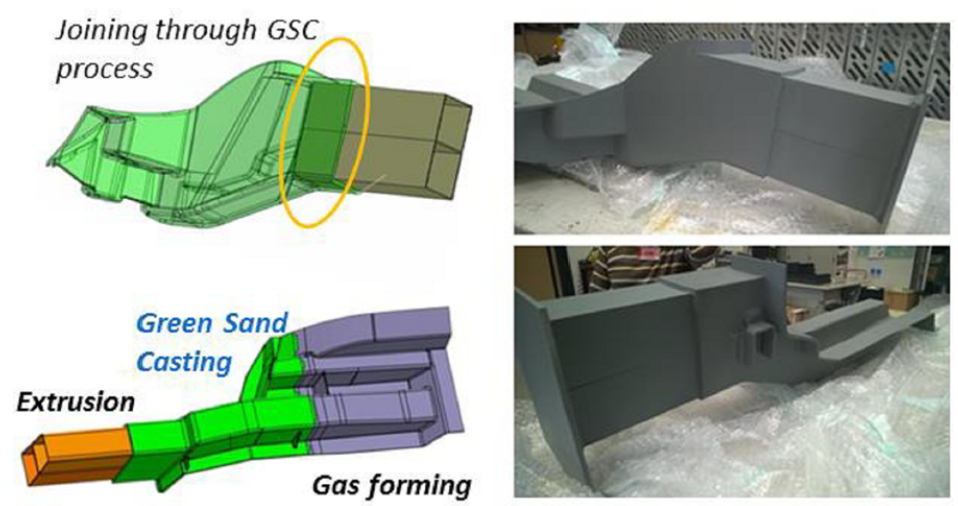

A rigid wall front crash, including also the front crossmember demonstrator was performed, to transfer the modelling improvement derived from correlation on the ECER95 virtual analysis (Figure 18). Besides, to validate the innovative interface between shot-gun and front rail, a series of durability push-pull test were performed. All these tests were successful.

Figure 18 The rigid wall front crash test set-up (see online version for colours)
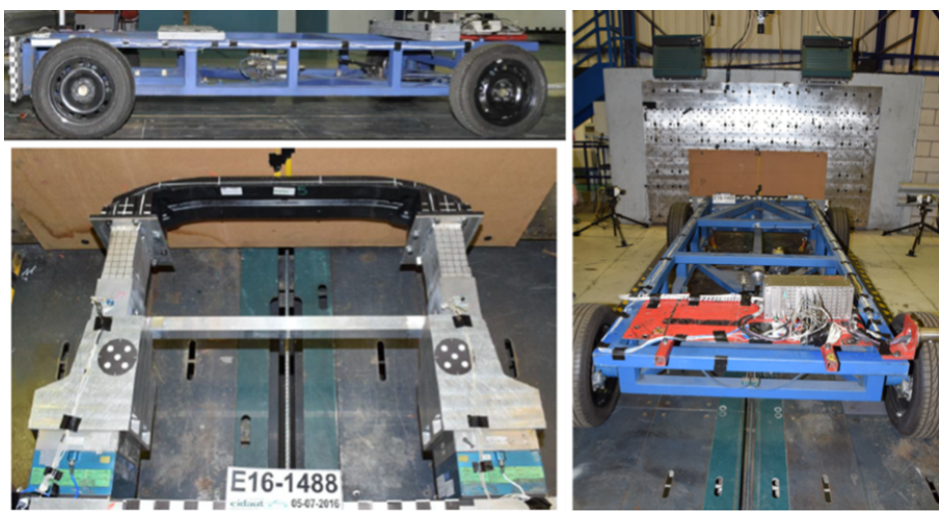

The weight saving due to EVolution design corresponded to $23 \%$ respect to Nido weight and, what is more, with an extended part assuring the crash performances.

To sum up, the redefined demonstrator was crash compliant, more extended in dimensions but lightweighted respect to the baseline, evidencing the EVolution philosophy to add mass only where it was necessary. 


\section{Conclusions}

Proposed solutions demonstrate an interesting lightweighting potential coupled with structural performances. Costs due to lightweighting and TAKT time are in line with the request for medium production volumes ( $\geq 30,000$ units/year) (Table 3) (Cischino et al., 2017).

Table 3 Cost analysis, manufacturing and economic viability

\begin{tabular}{|c|c|c|c|}
\hline Demonstrator & $\begin{array}{l}\text { Weight }(\mathrm{kg}) / \text { reduction with } \\
\text { respect to Nido weight }(\%)\end{array}$ & TAKT time & $\begin{array}{c}\Delta \text { cost-per-kg- } \\
\text { saved }(€)\end{array}$ \\
\hline Underbody & $21.05 / 30$ & $<6 \min$ & $\begin{array}{l}30 \% \text { of costs } \\
\text { saving due to } \\
\text { parts merging }\end{array}$ \\
\hline Structural node & $6.11 / 23$ & $5.5 \mathrm{~min}$ & $\begin{array}{l}\text { costs reduced of } \\
50 \% \mathrm{~b}\end{array}$ \\
\hline $\begin{array}{l}\text { Front } \\
\text { crossmember }\end{array}$ & $2.81 / 50 *$ & $<1 \min$ & 0.55 \\
\hline \multirow[t]{3}{*}{ Side Door } & $9.5 / 50 * *$ & $\begin{array}{c}-120 \text { min (compression } \\
\text { moulding) }\end{array}$ & 6.49 \\
\hline & & $-3 \min$ (stamp forming) & \\
\hline & & $\begin{array}{l}-5 \text { min (induction } \\
\text { heated tooling) }\end{array}$ & \\
\hline $\begin{array}{l}\text { Mechanical } \\
\text { subframe }\end{array}$ & $3.48 / 50$ & $4 \div 5 \min$ & 2.62 \\
\hline
\end{tabular}

*Reduction of Nanotough weight; **reduction of steel reference.

${ }^{\mathrm{a}}$ Weight and costs lower respect to baseline for 30,000 units/year; ${ }^{\mathrm{b}}$ any baseline ref. for 30,000 units/year; comparison with LPDC for 1000 units/year (Nido).

Current weight of the BiW, in line with the estimated target, is $113 \mathrm{~kg}$ vs. $160 \mathrm{~kg}$ of the full-Al baseline Nido. An FE-analysis on the virtual full vehicle indicates a good structural behaviour, considering EU standards of crash homologation and global static and dynamic performances (Table 4). It is remarkable that such results were obtained thank to an integrated approach, named design for purpose, where geometries, raw materials, process technologies, weight and performances have been treated as engineering design variables to achieve the EVolution project objectives.

A technological mock-up representing the full vehicle environment was conceived and manufactured to demonstrate the parts assemblies and showcase the project solution (Figure 19).

Further improvement can be achieved imagining applying extensively these technologies in all the BiW parts.

This optimisation, if done through the design for purpose approach, including the assembly and painting plants in the set of design variables, can lead to a smart reconfiguration or redefinition of the vehicle plants itself, in order to allow a streamlining of investments and ownership costs. 
Table 4 Global BiW/Full vehicle performances (see online version for colours)

\begin{tabular}{|c|c|c|c|}
\hline & Performance & Evolution status & Reference value \\
\hline \multirow{10}{*}{ 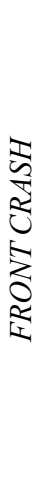 } & ECE R94: Firewall intrusion & Residual: $78 \mathrm{~mm}$ & $<120 \mathrm{~mm}$ \\
\hline & ECE R94: Steering column & Residual X: 4 mm & Residual $\mathrm{X}<60 \mathrm{~mm}$ \\
\hline & & Residual Z: 4 mm & Residual $\mathrm{Z}<50 \mathrm{~mm}$ \\
\hline & & Residual Y: $11 \mathrm{~mm}$ & Residual $\mathrm{Y}<60 \mathrm{~mm}$ \\
\hline & & Dynamic X: $12 \mathrm{~mm}$ & Dynamic $\mathrm{X}<100 \mathrm{~mm}$ \\
\hline & & Dynamic Z: $25 \mathrm{~mm}$ & Dynamic $Z<80 \mathrm{~mm}$ \\
\hline & & Dynamic Y: 34 mm & Dynamic $\mathrm{Y}<100 \mathrm{~mm}$ \\
\hline & ECE R94: PULSE & $33 \mathrm{~g}$ & $<40 \mathrm{~g}$ \\
\hline & ECE R94: Max A-pillar rearward & Residual $10 \mathrm{~mm}$ & Residual $<40 \mathrm{~mm}$ \\
\hline & displacement $(X)$ & Dynamic: $22 \mathrm{~mm}$ & Dynamic $<60 \mathrm{~mm}$ \\
\hline \multirow{4}{*}{ 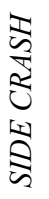 } & ECE R95: dynamic intrusion (Y) & $124 \mathrm{~mm}$ & $<150 \mathrm{~mm}$ \\
\hline & ECE R95: static intrusion (Y) & $98 \mathrm{~mm}$ & $<120 \mathrm{~mm}$ \\
\hline & ECE R95: V max (Y) & $9.0 \mathrm{~m} / \mathrm{s}$ & $<10 \mathrm{~m} / \mathrm{s}$ \\
\hline & ECE R95: V max (Y) & $8.1 \mathrm{~m} / \mathrm{s}$ & $<9 \mathrm{~m} / \mathrm{s}$ \\
\hline \multirow{2}{*}{$\underset{\curvearrowright}{\circledR}$} & Torsional stiffness (Kt) & $61,674 \mathrm{daNm} / \mathrm{rad}$ & $55,000 \mathrm{daNm} / \mathrm{rad}$ \\
\hline & $1^{\text {st }}$ torsional frequency & $51.1 \mathrm{~Hz}$ & $35 \mathrm{~Hz}$ \\
\hline
\end{tabular}

Figure 19 Details of work-in-progress EVolution technological mock-up with integrated demonstrators (see online version for colours)

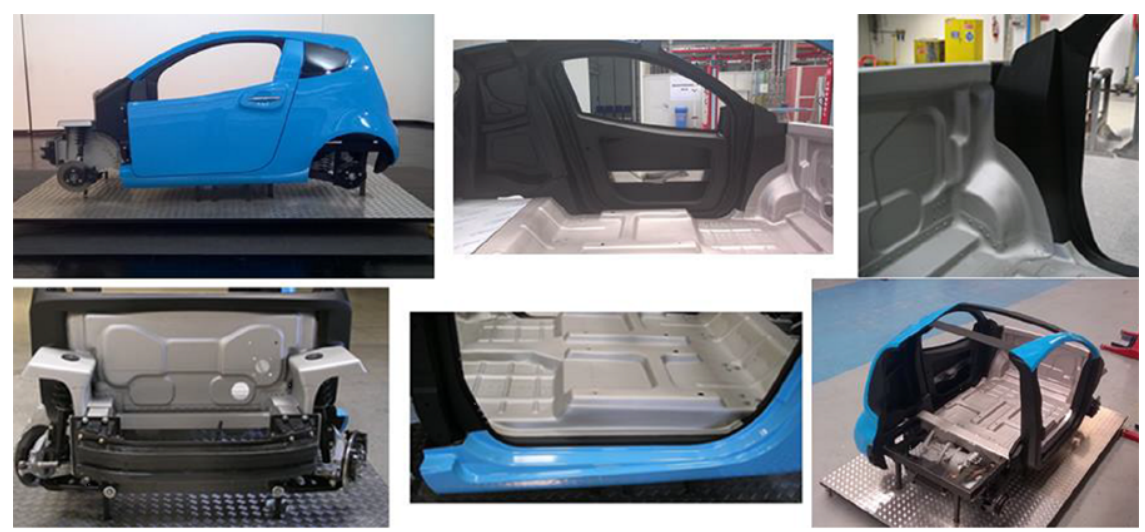

At full vehicle level, weight saving increases range with existing battery or maintain range with a smaller battery. Due to the fact the EV cost is directly related to battery size, being fixed the rate $€ / \mathrm{kWh}$ and the range, the lightweighting design will be a balance between weight and cost.

\section{Acknowledgements}

The research leading to these results has received funding from the European Union Seventh Framework Programme (FP7/2007-2013) under grant agreement no. 314744. 


\section{References}

Belingardi, G., Koricho, E.G. and Martorana, B. (2014) 'Implementation of composite and recyclable thermoplastic materials for automotive bumper subsystem', International Journal of Automotive Composites, Vol. 1, No. 1, pp.67-89.

Cischino, E., Vuluga, Z., Ezeiza, C.E., Benito, I.L., Mangino, E., de Claville Christiansen, J., Sanporean, C-G., Di Paolo, F., Kirpluks, M. and Cābulis, P. (2017) 'A concrete and viable example of multimaterial body: the EVolution project main outcomes', Procedia CIRP, Vol. 66, pp.300-305.

D'Annibale, A. (2014) An Innovative Methodology of Simulation and Testing for Sheet Bulk Metal Forming, PhD Thesis, University of L'Aquila, A.Y. 2013/2014

De La Calle, L.A., Elizetxea, E.C. and García, A.S. (2015) Device for Polymerizing Lactams in Molds, WO 2015/082728, 2015-06-1.

Drozdov, A.D., Sanporean, C-G. and de Jesper Christiansen, C. (2014) 'Enhancement of mechanical properties of polypropylene by blending with styrene-(ethylene-butylene)-styrene tri-block copolymer', Journal of Polymer Engineering, Vol. 34, No. 8, pp.765-774.

Dykes, R.J. and Logue, T.B. (2002) Roll Forming of Advanced Thermoplastic Composite Materials, Pyramid Mouldings Inc.

E-light (2010) Advanced Structural Light-Weight Architectures for Electric Vehicles, E-light, GA n. 266284, Theme GC-SST.2010.7-5.

Elmarakbi, A., El-Safty, S., Martorana, B. and Azoti, W. (2016) 'Nanocomposites for automotive: enhanced graphene-based polymer materials and multi-scale approach', International Journal of Automotive Composites, Vol. 2, No. 2, pp.155-166.

Fassbender, S., Urban, P., Dux, E., Hartmann, B., Eckstein, L. and Brockerhoff, M. (2012) Investigation of the Trade-off Between Lightweight and Battery Cost for an AluminiumIntensive Electric Vehicle, FKA, Report 106330.

García, A.S. and Palenzuela, G.L. (2011) Process and Device for Polymerizing Lactams in Molds, US 9290622 B2, 2011-06-23.

García, A.S., Moralez, D.U., Elizetxea, E.C., De La Calle, L.A., Hernandez, V.J.I., Casado, F.P. and Liceaga, O.M. (2016) Device for Polymerizing Lactams in Molds, EP 2743061 B1, 201604-06.

Harrison, N.R., Ilinich, A., Friedman, P., Singh, J. and Verma, R. (2013) Optimization of High Volume Warm Forming of Lightweight Sheet, SAE Technical Paper No. 2013-01-1170.

Khosrokhavar, R., Naderi, G., Bakhshandeh, G.R. and Ghoreishy, M.H.R. (2011) 'Effect of processing parameters on $\mathrm{PP} / \mathrm{EPDM}$ /organoclay nanocomposites using Taguchi analysis method', Iranian Polymer Journal, Vol. 20, No. 1, pp.41-53

Kirpluks, M., Cabulis, U., Ivdre, A., Kuranska, M., Zieleniewska, M. and Auguscik, M. (2016) 'Mechanical and thermal properties of high-density rigid polyurethane foams from renewable resources', J. Renew. Mater., Vol. 4, No. 1, pp.86-100.

Nanotough (2012) Toughened Hybrid Nanocomposites for High Performance Application, Nanotough, GA n. 213436.

Sanporean, C.G., Vuluga, Z., Radovici, C., Panaitescu, D.M., Iorga, M. deClaville Christiansen, J. and Mosca, A. (2014) 'Polypropylene/organoclay/SEBS nanocomposites with toughnessstiffness properties', RSC Adv., Vol. 4, p.6573.

Stichling, J. and Hasenberg, V. (2011) Recycling Lightweight Automobiles, PE INTERNATIONAL AG, 20 October.

Vuluga, Z., Panaitescu, D.M., Sanporean, C.G., Radovici, C., Gabor, R., Nicolae, C.A., Corobea, M.C., Iorga, M. and Florea, D. (2014) 'The effect of polystyrene blocks content and of type of elastomer blocks on the properties of block copolymer/layered silicate nanocomposites', Journal of Alloys and Compounds, Vol. 616, pp.569-576. 
Vuluga, Z., Sanporean, C.G., Iorga, M., Panaitescu, D.M., Corobea, M.C., Florea, D., Iancu, S. and Duldner, M. (2016) Masterbatch for Improving the Impact Strength of Polypropylene with Glass Fibre and Process for Obtaining It (Concentrat pentru imbunatatirea rezistentei la soc a polipropilenei cu fibra de sticla si procedeu de obtinere a acestuia), A 2015 00247, 131445 A2, 28 October, 2016.

Wang, Z., Lauter, C., Sanitther, B., Camberg, A. and Troester, T. (2016) 'Manufacturing and investigation of steel-CFRP hybrid pillar structures for automotive applications by intrinsic resin transfer moulding technology', International Journal of Automotive Composites, Vol. 2, Nos. 3-4, pp.229-243.

\section{Notes}

' 'Safety Car' was a Pininfarina research project developed with Miur, Centro Inox, CSI Spa, DOW, PI Technology in 2003-2004 where the first Nido city car has been strongly oriented towards safety for both the occupants and pedestrians in the event of a collision, by means of structural solutions, the distribution of the spaces and the management of the shape of the car itself.

${ }^{2}$ Patents: EP2338665 A1/ US 9,290,622B2 Process for polymerising lactams in moulds.

EP $2743061 \mathrm{~B} 1 / \mathrm{CN}$ 104086766A/ US2014/017268A1. Device for polymerising lactams in moulds.

WO2015/082728 A1/CN105793003. New device for polymerising lactams in moulds.

${ }^{3}$ Patents: EP2338665 A1/ US 9,290,622B2 Process for polymerising lactams in moulds.

EP 2743061 B1/ CN 104086766A/ US2014/017268A1. Device for polymerising lactams in moulds.

WO2015/082728 A1/CN105793003. New device for polymerising lactams in moulds. 